\title{
AS REPRESENTAÇÕES DOS TÉCNICOS E AUXILIARES DE ENFERMAGEM ACERCA DO TRABALHO EM EQUIPE NA UNIDADE DE TERAPIA INTENSIVA ${ }^{1}$
}

Helena Eri Shimizu²

Maria Helena Trench Ciampone ${ }^{3}$

Shimizu HE, Ciampone MHT. As representações dos técnicos e auxiliares de enfermagem acerca do trabalho em equipe na unidade de terapia intensiva. Rev Latino-am Enfermagem 2004 julho-agosto; 12(4):623-30.

Este estudo tem por objetivos explicitar e analisar as representações dos técnicos e auxiliares de enfermagem acerca do trabalho em equipe em UTI. Foi utilizada a abordagem qualitativa e, como referencial teórico metodológico, a Teoria das Representações Sociais. O material empírico constou de entrevistas com quatro técnicos e doze auxiliares de enfermagem que atuam nas UTIs de Clínica Médica, Cirúrgica e Pediátrica. Na análise dos dados, foi utilizada a técnica de análise de conteúdo, na modalidade de análise temática. Os resultados evidenciaram que os trabalhadores de enfermagem mantêm interação conflituosa, indicando a necessidade de adoção de modelos de gerenciamento de pessoal mais eficientes que contemplem a gestão de conflitos entre as equipes de enfermagem.

DESCRITORES: administração de recursos humanos em hospitais; unidades de terapia intensiva; enfermagem

\section{THE REPRESENTATIONS OF NURSING AUXILIARIES AND TECHNICIANS ABOUT TEAM WORK AT AN INTENSIVE-CARE UNIT}

This study aims to explain and analyze the representations of nursing auxiliaries and technicians about team work at an intensive-care unit. The qualitative approach was used and the Theory of Social Representations was adopted as a theoreticalmethodological reference framework. The empirical material was obtained from interviews with four technicians and twelve nursing auxiliaries working at the intensive care units of Medical, Surgical and Pediatric Clinics. The information obtained was analyzed by means of the content analysis technique, following the thematic analysis mode. Results indicated conflicting interaction among nursing workers, highlighting the need to implement more efficient staff management models that focus on conflict management actions among different nursing teams.

DESCRIPTORS: human resource administration in hospitals; intensive care units; nursing

\section{LAS REPRESENTACIONES DE TÉCNICOS Y AUXILIARES DE ENFERMERIA SOBRE TRABAJ OS EN EQUIPO EN UNIDADES DE CUIDADOS INTENSIVOS}

La finalidad de este trabajo es explicar y analizar las representaciones de técnicos y auxiliares de enfermería sobre trabajo en equipo en unidades de cuidados intensivos. Fue utilizado el abordaje cualitativo y, como referencia teóricametodológica, la Teoría de las Representaciones Sociales. El material empírico fue formado por entrevistas con cuatro técnicos y doce auxiliares de enfermería que actúan en unidades de cuidados intensivos en Clínica Médica, Quirúrgica y Pediátrica. Los datos fueron analizados utilizando la técnica de análisis de contenido, en la modalidad de análisis temática. Los resultados mostraron que la interacción entre los mencionados trabajadores es conflictiva, indicando que es necesario adoptar modelos más eficaces de administración de personal que contemplen la administración de conflictos entre los equipos de enfermería.

DESCRIPTORES: administración de personal en hospitales; unidades de terapia intensiva; enfermería

\footnotetext{
${ }^{1}$ Trabalho extraído da tese de doutorado intitulada: As representações sociais dos trabalhadores de enfermagem não enfermeiros (técnicos e auxiliares de enfermagem) sobre o trabalho em unidades de terapia intensiva em um hospital-escola apresentada ao Programa de PósGraduação Interunidade da Escola de Enfermagem da Universidade de São Paulo; ${ }^{2}$ Enfermeira, Doutor em Enfermagem, Professor Adjunto da Universidade de Brasília, e-mail: shimizu@unb.br; ${ }^{3}$ Enfermeira, Doutor em Psicologia Social, Professor Livre-Docente da Escola de Enfermagem da Universidade de São Paulo
} 
Contudo, observa-se que, no cotidiano das

O processo de trabalho nas UTIs demanda cooperação coletiva, uma vez que a gravidade e complexidade dos pacientes impõem a necessidade de lidar com equipamentos sofisticados, realizar avaliações clínicas constantes e procedimentos complexos, com tomadas de decisões imediatas.

A introdução maciça de novas tecnologias nos serviços de saúde de alta complexidade, como nas UTIs, tem não só modificado como conformado a subcultura nesses espaços de trabalho, isto é, interfere no sistema de valores, nas normas e nos sistemas de pensamento e de ação ${ }^{(1)}$. Assim sendo, é importante e necessário captar e analisar os sinais e símbolos culturais nesses serviços, especialmente a política de recursos humanos que mediatiza os termos da relação que ordena e determina significados muito interligados entre o sistema cultural e simbólico, que conformam, juntos, a identidade organizacional, que age tanto como elemento de comunicação e consenso como oculta e instrumentaliza as relações de dominação entre os diversos agentes ${ }^{(1)}$.

Em nossa prática percebemos que, nas UTIs, por existirem equipamentos modernos e sofisticados e profissionais, em geral, qualificados para o trabalho, predomina uma cultura em que a equipe tem a obrigação de salvar todos os pacientes ali internados, independente da gravidade e complexidade do quadro clínico. A ênfase no trabalho em equipe tem sido uma das estratégias para assistir os pacientes críticos, mas sabemos que existem muitas dificuldades para o seu desenvolvimento.

Em outro estudo, realizado com enfermeiras que atuam em UTIs ${ }^{(2-4)}$, constatamos que a dinâmica de trabalho dessas unidades dificulta o trabalho em equipe, pois os trabalhadores são pressionados o tempo todo para realizarem os cuidados sozinhos e com muita rapidez e eficiência. Verificamos também que as enfermeiras têm dificuldades para coordenar o trabalho em equipe nessa área, principalmente devido à falta de preparo para exercer essa função, originária da formação acadêmica insuficiente e reforçada pela ausência de treinamento nas instituições. Em suma, os resultados mostraram também que as enfermeiras precisam repensar a forma de gerenciamento de recursos humanos, sobretudo proporcionando espaços para ouvir os sentimentos e necessidades de todos os elementos da equipe. instituições de saúde, as enfermeiras ainda adotam postura bastante centralizadora e autoritária, o que tem dificultado o desenvolvimento de todos os elementos para realizar o trabalho em equipe ${ }^{(3-9)}$.

O trabalho em equipe constitui prática onde a comunicação entre os profissionais faz parte do exercício do cotidiano e onde os agentes operam a articulação das intervenções técnicas por meio da mediação simbólica da linguagem ${ }^{(10-11)}$. Assim, devem ser consideradas duas dimensões como inerentes ao trabalho em equipe: a articulação das ações e a interação dos profissionais ${ }^{(11)}$. A centralidade do trabalho em equipe está na obtenção de resultados que expressem a finalidade do trabalho, ou seja, a atenção integral às necessidades de saúde do paciente. Essa pode ser aprimorada em sua qualidade por meio da comunicação em busca de consenso entre os profissionais no cotidiano de trabalho. Assim, é fato que a centralidade do trabalho em grupo encontra-se na dinâmica das inter-relações e no vínculo entre os integrantes do grupo, o que, conseqüentemente, potencializa a realização do trabalho ${ }^{(11)}$.

Nessa perspectiva de compreensão caberia aos profissionais, principalmente àqueles que exercem o papel de coordenação, o desenvolvimento da sua potencialidade para trabalhar tanto em grupo como em equipe. Além disso, o papel de coordenação de grupo ${ }^{(12)}$ deve ser desenvolvido e potencializado não apenas nos gerentes, mas em todos os integrantes da equipe, pois auxilia o processo de interação e aprendizagem e o desenvolvimento de novas condutas e papéis, de modo ativo e participativo.

Acreditamos que os estudos que tomam como objeto o trabalho em equipe, a partir da percepção dos técnicos e auxiliares, são essenciais, pois podem fornecer elementos importantes para os enfermeiros refletirem sobre essa questão e, conseqüentemente, oferecer subsídios para aprimorar a coordenação do trabalho da equipe na enfermagem. Além disso, as pesquisas que mostram as percepções, sentimentos e explicitam as expectativas dos técnicos e auxiliares podem trazer contribuições para 0 exercício mais democrático do trabalho em equipe.

Assim, os objetivos deste estudo foram: - analisar as representações dos técnicos e auxiliares de enfermagem de UTI acerca do trabalho em equipe; - identificar as principais dificuldades e potencialidades para o desenvolvimento do trabalho em equipe na UTI. 
PERCURSO METODOLÓGICO

Optamos por utilizar a abordagem qualitativa para captar as representações dos técnicos e auxiliares de enfermagem acerca do trabalho em equipe na UTI. Elegemos como referencial teórico-metodológico a Teoria das Representações Sociais.

As representações sociais são teorias coletivas sobre o real, uma estrutura de implicações baseada em valores e idéias compartilhadas pelos grupos sociais, que rege as condutas desejáveis ou admitidas ${ }^{(13)}$.

Resgatar as representações sociais acerca da instituição pode ter implícito diferentes finalidades, tais como: conceder status às relações do conjunto, explicitar os aspectos não integrados, propor interpretação que tenha sentido para os indivíduos, indicar os limites e as transgressões, assegurar a identidade grupal, dramatizar os movimentos pulsionais ${ }^{(14)}$. Em suma, o trabalho em instituições permite a mobilização de representações que contribuem para a regulação endopsíquica e que asseguram as bases do sujeito com o conjunto social. Portanto, essas representações constituem o fundo da vida psíquica, no qual podem estar depositadas e contidas algumas partes da psique que escapam à realidade psíquica $^{(14)}$.

Diante do acima exposto, fica evidente a importância de compreendermos as representações sociais dos trabalhadores de enfermagem acerca do trabalho em equipe em uma área complexa como a UTI, pois nela se lida cotidianamente com a dor e a morte, o que acaba suscitando sentimentos diversos e complexos nos sujeitos/cuidadores, e que são possivelmente manifestados na convivência grupal.

O estudo foi realizado nas UTIs de Clínica Médica, Clínica Cirúrgica e Pediátrica do Hospital Universitário da Universidade de São Paulo. Participaram do estudo quatro técnicos e doze auxiliares de enfermagem, que doravante denominaremos apenas de trabalhadores de enfermagem.

É importante salientar que todos os cuidados relacionados aos aspectos éticos envolvidos na pesquisa foram devidamente observados pelas pesquisadoras, ou seja, o projeto foi submetido e aprovado pelo Comitê de Ética da instituição. Foi também solicitada autorização da instituição para a realização do estudo nas unidades acima mencionadas. Os sujeitos participantes do estudo manifestaram por escrito o seu consentimento pósinformado, tendo sido facultada a possibilidade de desistirem a qualquer momento de participar, sem qualquer tipo de prejuízo. Os seus nomes foram trocados por nomes fictícios, a fim de garantir o anonimato.

Optamos por realizar entrevistas individuais semiestruturadas, utilizando o seguinte roteiro: 1) como você percebe o trabalho em equipe na UTI? 2) como é o seu relacionamento com os colegas de trabalho? 3) como é o seu relacionamento com as enfermeiras? 4) como é o seu relacionamento com a chefia? As entrevistas foram gravadas e posteriormente transcritas na íntegra.

Para a análise das entrevistas, optamos por adotar a técnica de análise de conteúdo, especificamente a análise temática. Assim, a fim de buscar elementos para a compreensão das representações dos trabalhadores de enfermagem, acerca do trabalho em equipe, adotamos os seguintes procedimentos: a) leitura e re-leitura flutuante das entrevistas; b) mapeamento dos discursos individuais com base nos temas emergentes, definidos a partir da leitura flutuante e dos objetivos da pesquisa (destacandose as palavras e frases índices); e c) análise da dinâmica dos discursos (síntese das entrevistas, baseada nas palavras e/ou frases índices interpretadas pelo pesquisador). A seguir serão apresentados os temas apreendidos.

\section{APRESENTAÇÃO E DISCUSSÃO DOS DADOS}

As relações com a hierarquia

As representações dos sujeitos demonstram que nas UTIs existe hierarquia rígida, estabelecida pelo grau de escolaridade de cada um dos elementos da equipe de enfermagem, na qual a enfermeira (por ter nível universitário) fica no topo da cadeia de comando. A fala a seguir ilustra essa representação.

(...) é que aqui a gente tem uma hierarquia, que é claro, que eu como técnica, eu sei muito menos que uma enfermeira já formada. Isso é obvio. Sebastiana (téc. de enf.).

Essa divisão técnica e social estabelecida pelo grau de formação remonta ao século XIX, tendo início com a formalização dos agentes de enfermagem na Inglaterra, quando o hospital passa a ter o objetivo de cura dos pacientes $^{(15-16)}$.

As enfermeiras, ao deterem o monopólio do saber na área de enfermagem, exercem o papel dominante face aos demais trabalhadores da área, que são colocados do lado daqueles que não sabem, ou que se supõem não saberem $^{(17)}$, como mostra o depoimento. 
(...) tem muita enfermeira, ela não, não que ela não respeite, ela respeita, só que ela acha assim, que o auxiliar não sabe de nada, que ele está ali para acatar as ordens dela. Cristina (aux. de enf.).

A grande maioria dos trabalhadores de enfermagem das UTIs destacou que grande parte dos conflitos decorre da postura autoritária e centralizadora da enfermeira junto aos demais elementos da equipe de enfermagem.

Os discursos dos trabalhadores de enfermagem evidenciam também que, mesmo nas UTIs que têm maior número de enfermeiras assistenciais, elas não estão suficientemente próximas dos pacientes. Certamente essa situação contribui para que as enfermeiras se tornem inseguras para cuidar diretamente e resolver os problemas dos pacientes. Como conseqüência, os trabalhadores de enfermagem não podem contar com elas para serem parceiras e orientadoras dos cuidados aos doentes.

Nesse sentido, verifica-se que as formas de divisão do trabalho nas UTIs permitem às enfermeiras se desviarem do trabalho estressante com o doente internado, delegando essa tarefa aos trabalhadores de enfermagem de nível médio ${ }^{(18)}$.

Percebe-se ainda que as enfermeiras se ajustam facilmente ao papel de gerente da força de trabalho, atuando como representantes das instituições de saúde, reproduzindo a lógica do capital. O direcionamento do seu trabalho para as funções gerenciais lhes assegura a idéia de poder e ascensão social, em clara demonstração de consciência ingênua, que reforça o sentimento de fazer parte da cúpula gerencial da organização e aumenta o seu distanciamento dos demais elementos da equipe de enfermagem $^{(18)}$. Todavia, elas precisam reconhecer que vêm sendo usadas pela filosofia do sistema capitalista, que as distancia cada vez mais dos demais trabalhadores de enfermagem, a fim de que se dividam as forças de reivindicações conjuntas e se elimine um grupo maior de pressão nas organizações hospitalares ${ }^{(5)}$.

No cotidiano das UTIs, os trabalhadores de enfermagem, por não conseguirem suportar essa relação rígida e estereotipada, tentam romper com a divisão técnica e social entre os elementos da equipe da UTI.

O trabalho em equipe nas UTIs

O sistema cultural de uma instituição tem as seguintes finalidades: oferecer um sistema de valores e de normas a ser seguido e elaborar e estruturar uma maneira de pensar que orientam as condutas de seus diversos atores ${ }^{(19)}$. Esse sistema tem como propósito desenvolver um processo de formação e socialização dos diferentes atores, a fim de que cada um deles possa se definir em relação ao ideal proposto ${ }^{(19)}$.

Os trabalhadores de enfermagem têm a representação de que o trabalho em equipe nas UTIs envolve esforços de todos os elementos na busca do alcance de um único objetivo, que é o de prestar assistência de qualidade, entendida sobretudo como salvar a vida dos pacientes ali internados. Percebem ainda que, para o alcance desses objetivos, há a necessidade de se respeitar a hierarquia, a divisão de funções entre os elementos da equipe e ainda ter disposição para ajudar e partilhar os conhecimentos adquiridos com os colegas.

Olha! Aqui a gente tá junto por um objetivo só. É pra fazer o bem-estar da criança, cuidar da criança e formar mesmo uma boa equipe (...) o relacionamento aqui dentro do trabalho é isso aí, é todos estarem lutando por um objetivo só. Assim, tentando ajudar o outro. Na medida do possível e respeito. Tem uma hierarquia. É assim. Sebastiana (téc. de enf.).

Essas representações tratam da importância da existência da organização formal no grupo para que ocorra o trabalho em equipe. Possivelmente essa é a concepção de trabalho em equipe desenvolvida pela instituição para garantir a qualidade e produtividade do trabalho nas UTIs.

Nesse sentido, as representações dos trabalhadores evidenciam que faz parte da cultura das UTIs a conformação de trabalho em equipe, formalmente estruturada, de forma a prestarem a assistência ao paciente crítico com eficiência e eficácia. Contudo, percebe-se que esse modelo de trabalho em equipe não contempla as necessidades pessoais, não garante a qualidade do cuidado e não contribui para diminuir as angústias geradas pelo contato com os pacientes que se encontram em estado de extrema fragilidade. Na realidade, os trabalhadores realizam sacrifícios intensos para suportar a convivência em equipe no trabalho, como mostra a fala que segue.

Eu acho que a gente tem que ir além da nossa força que nós temos por dentro. Porque se no local de serviço a gente começa viver em desunião, é ruim para os próprios pacientes que estão dependendo da gente. Alice (aux. de enf.).

Para os trabalhadores de enfermagem, o que de fato caracteriza a existência do trabalho em equipe é a relação democrática, a não-rigidez, onde as pessoas 
possam ir além do que está estipulado na divisão técnica, isto é, que possam ultrapassar os limites da obrigação de cada um.

Uma instituição tem também o seu sistema simbólico, que comporta os mitos, ritos e sagas e que têm por função sedimentar a ação dos membros que ali trabalham, servir-lhes de sistema de legitimação e dar, assim, sentido à suas práticas cotidianas e à suas vidas ${ }^{(19)}$. Nesse sentido, a instituição pode se oferecer como objeto ideal a ser interiorizado, que dá vida aos sujeitos que nela trabalham, à qual todos devem manifestar a sua lealdade e até mesmo se sacrificar. Portanto, ela apresenta exigências e obriga todos a se moverem pelo orgulho do trabalho, a realizarem uma verdadeira missão de vocação salvadora $^{(19)}$.

Nas UTIs está muito presente o mito da eficiência da tecnologia, o que faz com que todos os que ali trabalham tenham orgulho de se dedicarem a essa área. Além disso, esse mito leva os trabalhadores a acreditarem que são capazes de resolver todo e qualquer problema dos pacientes ali internados. Como conseqüência, não há espaço para que os trabalhadores tenham dúvidas, incertezas ou insegurança de qualquer tipo.

Por fim, destaca-se que uma instituição produz um sistema imaginário, que pode se apresentar de duas formas: o imaginário enganador e imaginário motor ${ }^{(19)}$. 0 primeiro tem o poder de capturar os indivíduos na armadilha de seus próprios desejos de afirmação narcísica e de identificação, nas suas fantasias de onipotência ou na sua necessidade de amor, declarando-se capazes de responder aos seus desejos naquilo que apresentam de mais excessivo ou de arcaico e de transformar as fantasias em realidade. O segundo permite às pessoas liberdade para desenvolverem a imaginação criativa no trabalho.

As representações dos trabalhadores de enfermagem demonstram que, na UTI, se têm muito presente a dimensão do imaginário enganador, na medida em que ela é colocada como capaz de resolver os problemas mais complexos de saúde com eficiência e eficácia. A técnica e a tecnologia são colocadas como mediadoras entre os trabalhadores de enfermagem e 0 paciente. Como resultado, os trabalhadores de enfermagem se sentem mais seguros quanto à sua capacidade de se proteger da angústia de fragmentação despertada pelo contato com o objeto de trabalho. Nesse sentido, a UTI proporciona aos trabalhadores de enfermagem couraças sólidas do estatuto, da função e da identidade maciça da instituição $0^{(1)}$.
Nas UTIs, uma situação que costuma aproximar mais os elementos da equipe de saúde é o atendimento de parada cardíaca, pois todos sabem que o tempo é precioso para a recuperação sem seqüelas, do paciente, como mostra o depoimento abaixo.

O trabalho em equipe aqui de uma certa forma é bom. É bom. Porque assim, se você tem bastante, vamos supor: você tá aqui com uma criança, ela começa, ela tem uma parada, alguma coisa, então todo mundo se reúne para ajudar. Claro que nós se dividimos. Como o médico com a enfermeira; aí fica uma preparando as drogas, a outra já vai anotando o horário que foi feito as drogas (...). Alice (aux. de enf.).

Percebe-se que, nesse momento, existe, além da cooperação, cumplicidade e solidariedade entre os agentes envolvidos. No entanto, isso acaba logo após o atendimento do paciente, pois cada trabalhador volta a realizar as suas tarefas individualmente. Possivelmente, a solidariedade e a cumplicidade no trabalho não se mantém porque não estão previstas a negociação e a elaboração conjunta de um plano de ação comum aos pacientes e das situações vivenciadas no cotidiano de trabalho ${ }^{(10-20)}$.

Os trabalhadores de enfermagem percebem que nas UTIs não existe união entre os elementos da equipe de enfermagem. Eles identificam que existem grupos de pessoas que permanecem mais juntos no trabalho, que costumam se aproximar em alguns momentos e que geralmente isso ocorre quando acontece algum problema mais grave com os pacientes, como ilustra este depoimento.

Mas eu acho que as pessoas não têm consciência, acaba fazendo grupos. Então não chega a ser uma equipe geral. Sendo que, às vezes, sim. Mas sempre tem grupos. Rogério (aux. de enf.).

Verificou-se que, nas UTIs, apesar dos elementos da equipe de enfermagem permanecerem juntos em uma área física mais restrita, prestando cuidados aos pacientes, existe pouca interação entre eles e que essa se restringe a alguns momentos, como no atendimento de emergências, e que se dá a formação de alguns subgrupos. Quando não há vínculo entre os elementos do grupo, existe serialidade ${ }^{(21)}$, onde cada integrante do grupo é um indivíduo isolado, e esses indivíduos, enquanto números, são intercambiáveis um pelo outro. Nesse sentido, as representações dos trabalhadores de enfermagem evidenciam que, devido à falta de momentos e espaços para interação, o comportamento do grupo aproxima-se de uma série. 
As dificuldades e potencialidades para o trabalho em equipe

Os trabalhadores de enfermagem sentem que, pelo fato de passarem juntos grande parte do tempo, 0 relacionamento entre eles passa a ter características de um relacionamento familiar, onde existem afetos intensos e também momentos de tensão e conflitos.

(...) é como uma família, é seis horas passados junto. (...) eu acho que é igual em casa, com marido, com filho, com tudo, por mais que você se dê bem, por mais que tenha aquela harmonia tem um dia que as coisas ali que começa a pegar. Mas, de um modo geral é muito bom. Joana (téc. de enf.).

A família é o primeiro grupo a que pertencemos, a partir do nosso nascimento. É, portanto, na família que ocorrem os primeiros interjogos de adjudicação e assunção de papéis, que servem posteriormente como matrizes de atuação em outros grupos secundários ${ }^{(1)}$. A aprendizagem em grupos secundários, como no trabalho, tende a reativar em cada sujeito as experiências vividas no grupo familiar, assim como as ansiedades experimentadas naquela fase.

As representações dos trabalhadores de enfermagem acerca do trabalho em equipe na UTI demonstraram que a proximidade entre as pessoas no trabalho propicia o prazer, mas também causa grande sofrimento, advindo da ocorrência do interjogo de identificações entre enfermeiras, técnicos e auxiliares de enfermagem e, em alguns momentos, com pacientes, familiares e outros membros das equipes das UTIs, de modo indiscriminado. Certamente esses interjogos de identificações contribuem para dificultar mais ainda a convivência grupal dos trabalhadores das UTIs.

A identidade grupal se apresenta em dois níveis ${ }^{(21)}$. No primeiro, a identidade grupal é proporcionada por um trabalho em comum, no qual há modelos de interação e de comportamentos que são institucionalizados no grupo. Esse nível de identidade permite maior possibilidade de integração e interação dos indivíduos ou pessoas. No segundo, a identidade grupal não tem como base a interação, porque não existe a individualização entre os elementos que compõem o grupo. Essa é também chamada de identidade grupal sincrética. Alguns grupos só conseguem manter a identidade sincrética, o que traz sérias conseqüências para o grupo e também para o trabalho que desenvolvem.

Deve-se salientar que os grupos, para terem uma identidade autêntica e estável em áreas de atendimento que suscitam nos trabalhadores sentimentos diversos e complexos como dor, piedade e compaixão precisariam de um coordenador com preparo específico para trabalhar com grupos, para ajudá-los a discriminar entre as identificações sadias e as patógenas ${ }^{(1)}$.

Nas UTIs, no entanto, como esses aspectos e as relações interpessoais não são devidamente valorizados e adequadamente trabalhados, os trabalhadores de enfermagem se desgastam intensamente para suportarem a convivência grupal no cotidiano de trabalho e, ainda, vivem o temor de que os conflitos intragrupais possam ser manifestados nos pacientes.

Tem épocas que as pessoas estão se mordendo. De um olhar para a cara do outro, assim parece que vai, sabe? Assim, tipo querer matar. Sei lá, matar. Joana (tec. de enf.).

Essa situação é grave, pois quando o grupo não tem espaço para expor e trabalhar os sentimentos que emergem da convivência grupal, ele tende a manter apenas a identidade sincrética. E quando há cristalização dessa identidade, o grupo torna-se rígido, assume comportamento estereotipado e com tendência à burocratização ${ }^{(21)}$.

Apesar das condições desfavoráveis encontradas no cotidiano de trabalho nas UTIs, relacionados ao trabalho em equipe, verifica-se que os trabalhadores de enfermagem lutam constantemente para fortalecer a convivência no grupo onde estão inseridos, procurando valorizar o que existe de satisfatório na convivência grupal.

(...) o relacionamento é muito difícil com muita gente. Mas é que profissionalmente nós temos que procurar conviver bem com todos aqueles que nos cercam. Porque afinal de contas nós estamos aqui para formar uma equipe para formar uma equipe para prestar 0 melhor de nós para esses que precisa da gente. Alice (aux.de enf.).

Diversos aspectos relacionados ao trabalho em equipe são valorizados: um deles é a colaboração. A ajuda mútua existente no grupo certamente contribui para diminuição da sobrecarga e das tensões do trabalho. A disponibilidade para ajudar os colegas algumas vezes implica em ter de transgredir a divisão formal de funções, mas demonstra um estado de alerta com as necessidades do outro e uma visão de compromisso com o todo da unidade.

Outro fator muito evidenciado como importante e valorizado é a comunicação entre os elementos da equipe de enfermagem, o que permite que um trabalho pesado como o da UTI transcorra com mais tranqüilidade.

Isso é muito bom. Todo mundo fala a mesma língua. Vamos fazer? Vamos. Tem que fazer? Vamos fazer da melhor forma. É muito bom o trabalho daqui. Graça (téc. de enf.).

A comunicação é imprescindível para qualquer 
grupo, pois permite o reconhecimento do outro e de suas necessidades, bem como a sua incorporação. É, contudo, na aprendizagem conseguida no intercâmbio com o emissor que ocorre um maior ajustamento comunicacional $^{(22)}$. É nesse processo que ocorre uma modificação interna em cada um dos sujeitos, e essa modificação emerge do reconhecimento do outro e de sua incorporação.

Os trabalhadores de enfermagem dão também muita importância para a criação do vínculo entre eles. Quando existe vínculo, cada sujeito reconhece o outro como diferenciado de si, mas ao mesmo tempo relacionado com ele ${ }^{(22)}$. Assim, ambos se reconhecem como diferenciados e articulados no interjogo contínuo dos processos de comunicação e aprendizagem.

Evidenciam ainda que, para haver trabalho em equipe, é preciso que as pessoas tenham a liberdade para expor as questões pessoais, vividas no cotidiano, aos colegas. Nesse sentido, as relações no grupo não se devem dar apenas formalmente, pois em alguns momentos a formalidade precisa ser deixada de lado, para que possam ser mais sensíveis às questões pessoais do colega.

Enfim, os trabalhadores de enfermagem têm a representação de que o trabalho em equipe pode ser melhorado, ou seja, pode responder à necessidade de incluir além dos objetivos implícitos à tarefa do cuidar, os dos sujeitos e do grupo de trabalho.

\section{CONSIDERAÇÕES FINAIS}

As representações dos trabalhadores de enfermagem das UTIs demonstram que o trabalho em equipe significa a união de esforços de todos os elementos para salvar a vida dos pacientes, o que tem sido

\section{REFERÊNCIAS BIBLIOGRÁFICAS}

1. Ciampone MHT. Grupo Operativo: construindo as bases para o ensino e a prática na enfermagem. [tese]. São Paulo (SP): Escola de Enfermagem/USP; 1998.

2. Shimizu HE. O sofrimento e o prazer no trabalho das enfermeiras que trabalham em UTI em um hospital-escola. [dissertação]. São Paulo (SP): Escola de Enfermagem/USP; 1996.

3. Shimizu HE. As representações sociais dos trabalhadores de enfermagem não enfermeiros (técnicos e auxiliares de enfermagem) sobre o trabalho na Unidade de Terapia Intensiva em um hospital-escola. [tese]. São Paulo (SP): Escola de Enfermagem/USP; 2000. satisfatoriamente alcançado. Entretanto, os trabalhadores mostram que a forma como está estruturado o trabalho em equipe nas UTIs, apesar de garantir a produtividade e qualidade do cuidado, impede a obtenção de maior satisfação no trabalho, sobretudo porque não há espaço para os integrantes do grupo manifestarem as suas necessidades e angústias a ele relacionadas. Fica evidente que se essas questões relativas à convivência grupal não forem devidamente valorizadas existe a possibilidade de instalação de mecanismos de defesa, como o grupo fecharse em si mesmo, com tendência a burocratizar-se e, conseqüentemente, tornar-se mais rígido e resistente a mudanças $^{(1-3)}$.

Os trabalhadores de enfermagem evidenciam também que a estrutura do serviço de enfermagem rigidamente hierarquizada, onde a enfermeira assume postura autoritária e centralizadora junto aos demais elementos, contribui sobremaneira para dificultar o desenvolvimento do trabalho em equipe. Nesse sentido, os trabalhadores apontam a necessidade das enfermeiras repensarem e modificarem o modelo de gerenciamento de recursos humanos que vêm desenvolvendo. Um modelo mais flexível parece ir ao encontro do anseio manifestado nas representações dos trabalhadores, sendo desejável maior horizontalidade nas decisões e poderes, bem como maior participação de todos os trabalhadores de enfermagem.

Enfim, as representações dos trabalhadores de enfermagem acerca do trabalho em equipe demonstram a necessidade de criação de espaços institucionais que proporcionem maior interação entre os membros da equipe, onde os sujeitos possam verbalizar os sentimentos de ansiedade, de insatisfação, de dor, de insegurança e de conflito, vivenciados nas relações com os pacientes, com familiares, com a equipe de trabalho e com a instituição.

4. Shimizu HE, Ciampone MHT. O sofrimento e o prazer no trabalho das enfermeiras que trabalham em UTI em um hospital-escola. Rev Esc Enfermagem USP 1999 março; 33(1):95-106.

5. Ciampone MHT. Administração participativa: análise de uma experiência vivenciada por um grupo na prática de enfermagem hospitalar. [dissertação]. São Paulo (SP): Escola de Enfermagem/USP; 1987.

6. Kreutz I. O trabalho em equipe na enfermagem. [dissertação]. São Paulo (SP): Escola de Enfermagem/USP; 1993.

7. Lima MAD. O trabalho da enfermagem na produção de cuidados de saúde no modelo clínico. [tese]. Ribeirão Preto (RP): Escola de Enfermagem/USP; 1998. 
8. Ferraz C. Gerenciamento de enfermagem: do modelo burocrático à administração flexível. São Paulo (SP): Frôntis; 1997.

9. Kurcgant P. A liderança na administração do pessoal de enfermagem segundo a percepção das enfermeiras que vivenciam essa prática em hospital. [tese]. São Paulo (SP): Escola de Enfermagem/USP; 1992.

10. Peduzzi M. Equipe multiprofissional de saúde: a interface entre trabalho e interação. [tese]. Campinas (SP): Faculdade de Ciências Médicas/UNICAMP; 1998.

11. Peduzzi M, Ciampone MHT. Trabalho em equipe e trabalho em grupo no programa saúde da família. Rev Bras Enfermagem 2000 dezembro; 53(Especial):143-7.

12. Pichon-Rivière $E$. O processo grupal. São Paulo (SP): Martins Fontes; 1994.

13. Moscovici S. A Representação Social da Psicanálise. Rio de Janeiro (RJ): Zahar; 1978.

14. Kães R. Realidade psíquica e sofrimento nas instituições. In: Kães R, Bleger J, Enriquez E, Fornari F, Roussilon R, Vidal JP. A instituição e as instituições: estudos psicanalíticos. São Paulo (SP): Casa do Psicólogo; 1991. p. 1-39.

15. Almeida MCP, Rocha JS. O saber da enfermagem e a sua dimensão prática. São Paulo (SP): Cortez; 1989.

16. Silva GB. Enfermagem profissional: análise crítica. São Paulo (SP): Cortez; 1986.

17. Nakamae DD. Novos caminhos da enfermagem: por mudanças na prática. São Paulo (SP): Cortez; 1978.

18. Alves M. Causas do absenteísmo na enfermagem: uma dimensão do sofrimento no trabalho. [tese]. São Paulo (SP): Escola de Enfermagem/USP; 1996.

19. Enriquez E. A organização em análise. Petrópolis (RJ): Vozes; 1997.

20. Saloum NH, Boemer MR. A morte no contexto hospitalar as equipes de reanimação cardíaca. Rev Latino-am Enfermagem 1999 dezembro; 7(5):109-19.

21. Bleger J. O grupo como e o grupo na ins1tituição. In: Bleger J. Temas de psicologia. São Paulo (SP): Martins Fontes; 1989.

22. Quiroga AP. O conceito de grupo e os princípios organizadores da estrutura grupal no pensamento de Enrique Pichon Rivière. Temas de Psicologia Social 1977; 1:1-18. 